\title{
Lasp-1, a Novel Type of Actin-Binding Protein Accumulating in Cell Membrane Extensions
}

\author{
Valérie Schreiber, ${ }^{1}$ Christel Moog-Lutz, ${ }^{1}$ Catherine H. Régnier, ${ }^{1}$ \\ Marie-Pierre Chenard, ${ }^{2}$ Hélène Boeuf, ${ }^{1}$ Jean-Luc Vonesch, ${ }^{1}$ \\ Catherine Tomasetto, ${ }^{1}$ and Marie-Christine Rio ${ }^{1}$ \\ ${ }^{1}$ Institut de Génétique et de Biologie Moléculaire et Cellulaire, CNRS/ \\ INSERM/ULP Strasbourg, Illkirch, Strasbourg, France \\ ${ }^{2}$ Service d'Anatomie Pathologie Générale, Centre Hospitalier \\ Universitaire de Hautepierre, Strasbourg, France \\ Accepted September 1, 1998.
}

\begin{abstract}
The Lasp-1 gene, which has been localized to the q12q21 region of human chromosome 17 , is amplified and overexpressed in human breast cancers. In addition to the previously reported LIM and SH3 domains of Lasp-1, we report here the identification of an actin-binding domain in the core of the protein. This domain is functional as we demonstrate that Lasp-1 binds actin in vivo and in vitro. In addition, confocal analysis of the Lasp-1 subcellular distribution shows that the protein is colocal-
\end{abstract}

ized with actin at peripheral cell extensions in individual epithelial cancer cells and in transformed fibroblastic cells. Moreover, Lasp- 1 is tyrosine phosphorylated in fibroblast cell lines transformed by a constitutively active form of c-Src (c-Src ${ }^{\text {Y527F }}$ ). Altogether, our results show that Lasp-1 defines a new type of actin-binding protein and suggest that the protein may play a role in a signaling pathway involved in the organization of the cytoskeleton.

\section{Introduction}

Human Lasp-1 (LIM and SH3 protein) cDNA (Accession No. X82456) was cloned from a breast cancer-derived metastatic lymph node cDNA library (1). The human gene maps to the q12-q21 region of chromosome 17 and is amplified and overexpressed in $12 \%$ of breast cancers (2), suggesting that Lasp-1 may contribute to molecular processes involved in breast cancer genesis and/or progression. Lasp-1 has been well conserved throughout evolution, with the mouse

V. Schreiber's present address is Ecole Supérieure de Biotechnologie de Strasbourg, UPR 9003 du CNRS, Bd S. Brant 67400 Illkirch, C.U. Strasbourg, France.

Address correspondence and reprint requests to: Dr. MarieChristine Rio, Institut de Génétique et de Biologie Moléculaire et Cellulaire, CNRS/INSERM/ULP Strasbourg, BP 163 , 67404 Illkirch, Cedex C.U. Strasbourg, France. Phone: (33) 3886534 24; Fax: (33) 3886532 01; E-mail: rio@igbmc.u-strasbg.fr
cDNA (Accession No. X96973) showing 96\% homology to its human counterpart (3). Expression analyses performed on human (4) and mouse tissues (3) revealed an almost ubiquitous basal expression of the gene.

Human Lasp- 1 encodes a protein of 261 residues, containing at its $\mathrm{N}$ - and C-termini a LIM (Lin-11, Isl-1 and Mec-3) and SH3 (Src homology 3) domain, respectively (4). The LIM domain is a two-zinc finger-like structure found in an increasing number of proteins (for review, see refs. 5,6). It is found as a unique structural motif in "LIM-only" proteins, but it is also often associated with additional structural and functional domains, including DNA-binding homeodomains, serine/threonine protein kinases, SH3binding sites, or GAP domains (6). The LIM domain has been shown to mediate proteinprotein interactions, by dimerization with LIM 
domains of partner proteins $(7,8)$ or through interaction with tyrosine-containing tight turn or basic helix-loop-helix motifs $(9,10)$. The SH3 domain, which was first identified in the nonreceptor protein tyrosine kinase c-Src, is involved in protein-protein interactions through binding to proline-rich sites (for review see ref. 11).

Protein-protein interactions mediated through LIM and SH3 domains are known to be involved in the regulation of protein activity. For example, the LIM domains of muscle LIM protein (MLP) promote differentiation of myogenic cell lines (12), and the $\mathrm{SH} 3$ domains of $\mathrm{c}-\mathrm{Src}$ and $\mathrm{c}-\mathrm{Abl}$ have negative autoregulatory effects on the catalytic and oncogenic activities of these tyrosine kinases $(13,14)$. Moreover, LIM and SH3 domains participate in regulating the subcellular localization of proteins interacting with the cytoskeleton. Thus, the third LIM domain of paxillin and the $\mathrm{SH} 3$ domains of Cas and of activated c-Src ${ }^{\mathrm{Y} 527 \mathrm{~F}}$ were shown to be responsible for the localization of the proteins to focal adhesion sites (15-17), whereas the SH3 domains of Grb2 and phospholipase $\mathrm{C} \gamma$ (PLC $\gamma$ ) were required for the localization of these proteins to sites of membrane ruffling and the actin cytoskeleton, respectively (18).

The presence of LIM and SH3 domains suggested that Lasp-1 might act as an adaptor protein involved in a cell-signaling pathway. In this report, we show that in addition to the LIM and SH3 domains, Lasp-1 contains two actin-binding repeats. Lasp- 1 and actin colocalize in membrane extensions of epithelial cancer cells and transformed fibroblastic cells, and directly interact in vitro. Moreover, Lasp-l is tyrosine phosphorylated in fibroblastic cells transformed by an activated mutant of c-Src. Altogether, our results suggest that Lasp-1 might participate in the modifications of the cytoskeleton that occur during tumor progression.

\section{Materials and Methods}

\section{Cell Culture and DNA Constructs}

The SK-OV-3 ovarian cancer, the BT-474, MDAMB-361, MCF7 human breast cancer, and monkey kidney COS-1 cell lines were provided by the American Type Culture Collection (ATCC; Rockville, $M D$ ), routinely maintained in our laboratory and cultured as recommended. The cell lines 3T3, 3T3/N overexpressing wild-type c-Src and the 3T3/A overexpressing the activated point mutant $c-S{ }^{\mathrm{Y} 527 \mathrm{~F}}(19,20)$ were maintained in
Dulbecco's modified Eagles medium (DMEM) (4.5 g/L glucose) supplemented with $10 \%$ fetal calf serum (FCS) and $1 \%$ gentamycin.

A Bam HI fragment $(1.3 \mathrm{~kb})$ corresponding to the open reading frame of the human Lasp-1 cDNA (Accession No. X82456) was cloned into the BamHI site of the pCMVneo vector (21) to generate the pLasp expression vector. Fragments encoding full-length mouse Lasp-1 (Accession No. X96973 [3]) or truncated forms were amplified by polymerase chain reaction (PCR) and cloned into the NheII site of the $\mathrm{pBC}$ vector (22). The full-length (residues 1-263), N-terminal portion (residues 1-130) and C-terminal portion (residues 131-263) of mouse Lasp-1 fused to GST were used to generate GST-Lasp, GST-NLasp, and GST-C-Lasp fusion proteins, respectively. Full-length mouse Lasp-1 cDNA was cloned into the NheI site of the pAT4 vector (23) to generate the pAT4Lasp expression vector.

\section{Antibodies}

To generate the pab805 polyclonal anti-Lasp-1 antibody, the synthetic peptide KYHEEFEKSRMGPSGGEGM (corresponding to residues 121-139 of human Lasp-1) was coupled to ovalbumin through an additional N-terminal cysteine residue and injected into New Zealand rabbits. This peptide is strictly conserved between human and mouse Lasp-1 $(3,4)$. Immunoreactive serum was affinity purified against the synthetic peptide coupled to Sulfolink coupling gel (Pierce, Rockford, IL) using conditions described by the manufacturer. The $4 \mathrm{Gl} 0$ monoclonal anti-phosphotyrosine and the 327 monoclonal anti c-Src antibodies were generous gifts from D. Morrison (National Cancer Institute, Frederick, MD) and J. Brugge (ARIAD Pharmaceuticals Inc., Cambridge, MA), respectively. The monoclonal anti-GST antibody was obtained from Dr. Y. Lutz (IGBMC, Illkirch, France). Horse-radish peroxidase-conjugated donkey anti-rabbit or goat anti-mouse antibodies, Texas Red-conjugated donkey anti-rabbit, and FITC-conjugated donkey anti-mouse antibodies were purchased from Jackson ImmunoResearch Laboratories, Inc. (West Grove, PA). The AC-40 monoclonal anti-actin antibody and rabbit muscle actin were from Sigma (St. Louis, MO).

\section{Immunoprecipitation}

Cells were rinsed with phosphate buffered saline (PBS) and lysed 10 min on ice in TBS-triton 
buffer $(20 \mathrm{mM}$ Tris $\mathrm{HCl}, \mathrm{pH} 8,150 \mathrm{mM} \mathrm{NaCl}, 1 \%$ Triton X-100, 10\% glycerol, $1 \mathrm{mM}$ PMSF, $1 \mathrm{mM}$ sodium orthovanadate, $20 \mathrm{mM}$ sodium molybdate, $1 \mathrm{mM} \mathrm{NaF}$ ). Lysates were clarified by centrifugation and protein content was determined by the Bradford method (Biorad Laboratories, Richmond, CA). Immunoprecipitation was performed with $0.5 \mathrm{mg}$ of proteins. After preclearing with protein A-Sepharose beads (Pharmacia, Uppsala, Sweden), lysates were incubated with antibodies for $2 \mathrm{hr}$ at $4^{\circ} \mathrm{C}$, then $1 \mathrm{hr}$ with protein A Sepharose. Bound immune complexes were washed three times in LSB buffer $(50 \mathrm{mM}$ Tris $\mathrm{HCl}, \mathrm{pH} 7.8,250 \mathrm{mM} \mathrm{NaCl}, 0.1 \% \mathrm{NP} 40,0.4 \mathrm{mM}$ MPSF, $1 \mathrm{mM}$ sodium orthovanadate, $20 \mathrm{mM}$ sodium molybdate, $1 \mathrm{mM} \mathrm{NaF}$ ). The pellets were resuspended in Laemmli buffer and heated 5 min at $100^{\circ} \mathrm{C}$ before analysis by SDS-polyacrylamide gel electrophoresis (PAGE).

\section{SDS-PAGE and Western Blotting}

Cell extracts were resolved by $10 \%$ SDS-PAGE and electrotransferred to nitrocellulose sheets (Schleicher and Schuell, Dassel, Germany). For Western immunoblotting analysis, blots were incubated with pab805 anti-Lasp-1 (diluted 1/20000), 4G10 anti-phosphotyrosine (1/10), anti-actin (1/4000), or anti-GST (1/1000) antibodies, then probed with horse-radish peroxidase-conjugated donkey anti-rabbit or goat anti-mouse antibodies (diluted 1/1000). Immunoreactivity was detected by enhanced chemiluminescence (NEN, Boston, MA) according to the recommendations of the manufacturer.

For farwestern blotting analysis, blots were incubated overnight in $50 \mathrm{mM}$ Tris- $\mathrm{HCl}, \mathrm{pH} 8$, $150 \mathrm{mM} \mathrm{NaCl}, 1 \mathrm{mM}$ DTT, $0.3 \%$ Tween, and 3\% bovine serum albumin (BSA), then $2 \mathrm{hr}$ in binding buffer ( $2 \mathrm{mM}$ Tris- $\mathrm{HCl}$, pH $8,0.2 \mathrm{mM} \mathrm{CaCl}_{2}$, $0.2 \mathrm{mM}$ ATP, $0.5 \mathrm{mM}$ DTT) in the presence of 25 $\mu \mathrm{g} / \mathrm{ml}$ actin. After two washes with PBS, $0.1 \%$ Tween blots were subjected to immunodetection with the AC-40 monoclonal anti-actin antibody as described above.

\section{GST-Pull Down Assay}

COS- 1 cells were transiently transfected by calcium-phosphate coprecipitation (24) with $10 \mu \mathrm{g}$ of pBC-derived vectors. Forty eight hours later, glutathione- $S$-transferase (GST)-pull down assays were performed as described (22). Briefly, cells were scraped in $1 \mathrm{ml}$ PBS, pelleted, and resuspended in $150 \mu$ l lysis buffer ( $20 \mathrm{mM}$ Tris
$\mathrm{HCl}, \mathrm{pH} 7.5,0.4 \mathrm{M} \mathrm{NaCl}, 5 \mathrm{mM}$ DTT, 20\% glycerol, $0.4 \mathrm{mM}$ PMSF, I mM sodium orthovanadate, $20 \mathrm{mM}$ sodium molybdate, $1 \mathrm{mM} \mathrm{NaF}$ ). After two cycles of freezing and thawing, lysates were clarified by centrifugation and protein content was determined by the Bradford method. Four hundred micrograms of protein extracts were incubated $2 \mathrm{hr}$ with glutathione (GSH)Sepharose beads (Pharmacia, Uppsala, Sweden) in $1 \mathrm{ml}$ of LSB buffer. Depending on the experiment, washing stringencies varied. For endogenous actin copurification, beads were washed three times with LSB buffer. For farwestern blot analysis, beads were washed more stringently, once with $50 \mathrm{mM}$ Tris $\mathrm{HCl}, \mathrm{pH} 7.8,0.1 \% \mathrm{NP} 40$, I $\mathrm{M} \mathrm{NaCl}, 0.4 \mathrm{mM}$ PMSF, followed by two washes with $50 \mathrm{mM}$ Tris $\mathrm{HCl}, \mathrm{pH} 7.8,0.5 \%$ NP40, $250 \mathrm{mM} \mathrm{NaCl}, 0.4 \mathrm{mM}$ PMSF. The samples were then resuspended in Laemmli buffer, boiled for $5 \mathrm{~min}$, and analyzed by SDS-PAGE and immunoblotting as described above.

\section{Immunofluorescent Labeling and Confocal Laser Scanning Microscopy}

BT-474 or SK-OV-3 cells were grown for $24 \mathrm{hr}$ on glass coverslips in 100-mm dishes, washed twice with PBS, fixed 30 min in PBS containing $2 \%$ paraformaldehyde, then permeabilized 10 min in PBS, $0.1 \%$ Triton $\mathrm{X}-100.3 \mathrm{~T} 3$ and $3 \mathrm{~T} 3 / \mathrm{A}$ cells were grown for $24 \mathrm{hr}$ on glass coverslips, then transfected with $50 \mathrm{ng}$ of pAT4Lasp vector together with $10 \mu \mathrm{g}$ of pBluescript carrier DNA, and incubated $24 \mathrm{hr}$ at $37^{\circ} \mathrm{C}$ before fixation as described above. Permeabilized cells were incubated $30 \mathrm{~min}$ in PBS, $0.1 \%$ Triton $\mathrm{X}-100,3 \% \mathrm{BSA}$, and $1 \mathrm{hr}$ with the first antibody diluted in PBS. Dilutions were $1 / 2000$ for purified pab805 anti-Lasp-1 antibody and 1/200 for monoclonal anti-Src 327 antibody. After three washes with PBS containing $0.1 \%$ Triton X-100, cells were incubated $1 \mathrm{hr}$ with the secondary antibodies diluted in PBS (1/200 for Texas Red-conjugated donkey anti-rabbit and 1/40 for FITC-conjugated donkey antimouse). Actin was labeled by adding $0.0005 \%$ FITC-phalloidin (Molecular Probes, Eugene, OR) after $40 \mathrm{~min}$ in the secondary antibody labeling mix. DNA was counterstained with Hoechst 33258 and the coverslips were mounted on microscope slides in glycerol/PBS (4/1) containing $5 \%$ propylgallate. Observations were made either with a Microphot-FXA microscope (Nikon Corporation, Tokyo, Japan) or with a confocal microscope equiped with an 


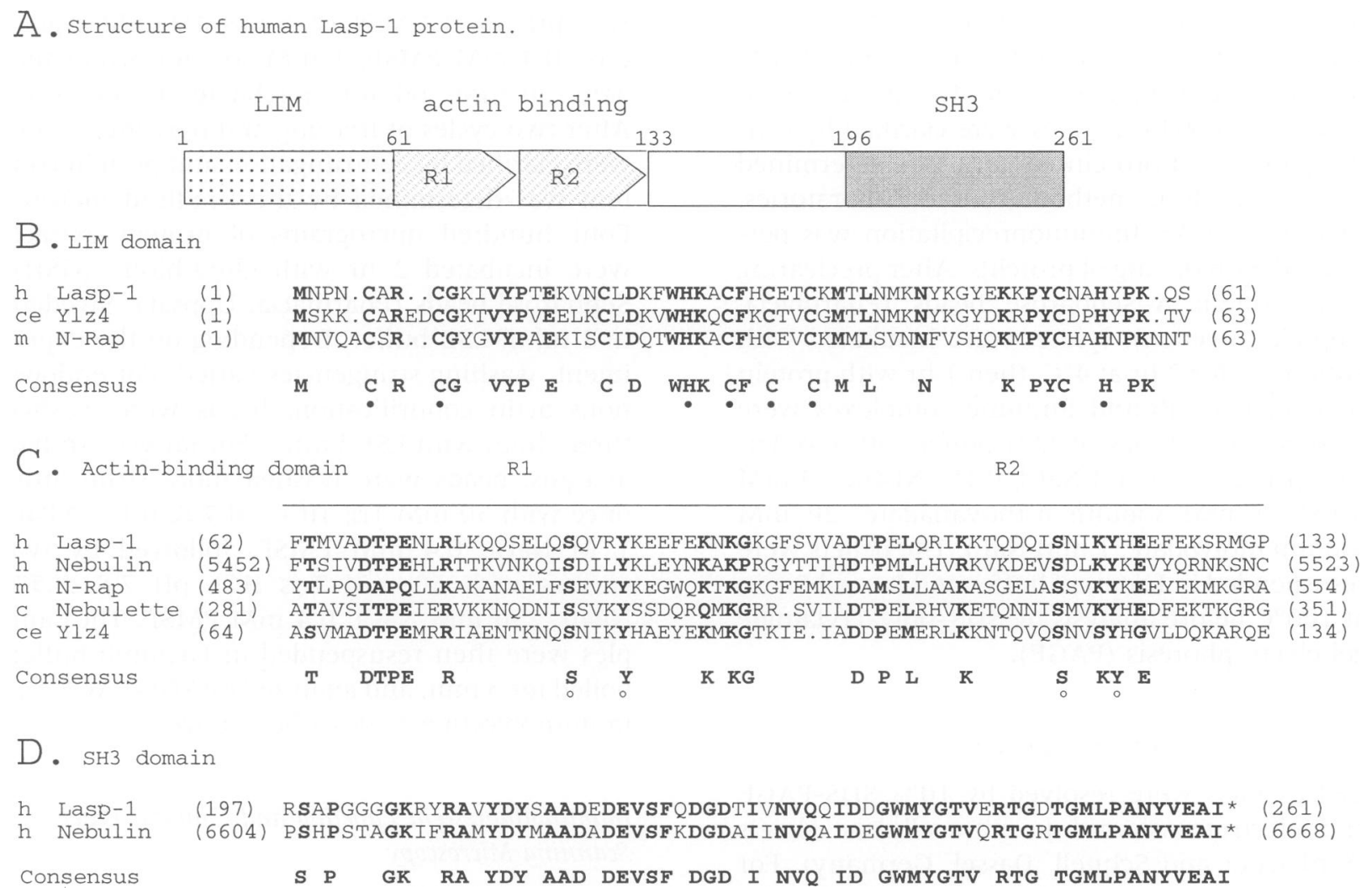

Fig. 1. Lasp-1 protein organization. (A) Schematic representation of human Lasp-1 (261 amino acids). The LIM domain, actin-binding repeats ( $\mathrm{R} l$ and R2), and SH3 domain are dotted, hatched, and gray, respectively. Alignment of the LIM (B), actinbinding (C), and SH3 (D) domains of Lasp-1 with corresponding domains of N-Rap, nebulin, nebulette, and Ylz4. h, human; m, mouse; c, chicken; ce, Caenorhabditis elegans. Amino acids are designated by the one-letter code, and numbers indicate their position. Gaps (.) are introduced to optimize the alignment.

argon-krypton laser and suitable barrier filters (Leica TCS4D, Heidelberg, Germany).

\section{Immunohistochemistry}

Immunohistochemical analysis was performed on paraffin-embedded tissue sections of breast carcinoma samples, using a peroxidase-antiperoxidase system (DAKO, Carpinteria, CA) for revelation as previously described (25).

\section{Sequence Analysis}

Sequence comparison of the human and mouse Lasp-1 protein sequence with protein databases were performed with the GCG sequence analysis package (Wisconsin Package, version 8.1-UNIX, Genetic Computer Group).
Residues conserved in all (B, D) or in four out of five $(C)$ sequences are in boldface and reported in the consensus sequence. In (B), cysteines and histidines involved in the LIM domain are shown by closed circles. In $(C)$, only the repeats of nebulin, $\mathrm{N}$-Rap, and nebulette that are the most homologous with those of Lasp-l are represented. The conserved SD-YK motifs of nebulin-like actin-binding repeats are marked by open circles. In (D), the asterisks indicate the last residue of the proteins.

\section{Results}

Lasp-1 Contains Two Actin-Binding Motifs

Comparison of the human Lasp-1 protein sequence with protein databases revealed that in addition to the LIM and the SH3 domains (4), Lasp-l contains two tandemly repeated actin binding modules ( $R 1$ and $R 2$, residues 62-133; Fig. 1 A and C). These repeats are similar to those identified in nebulin (Fig. 1C), a giant filamentous actin-binding protein of $\sim 800 \mathrm{kD}$ that is abundant in vertebrate skeletal muscle where it acts as a "molecular ruler" $(26,27)$. The amino acid sequence of nebulin shows that $97 \%$ of this molecule consists of 185 repetitions of an $\sim 35-$ residue module (Fig. 1C), each module constituting the basic structural unit of the actin-binding domain $(26-28)$. Such actin-binding repeats 


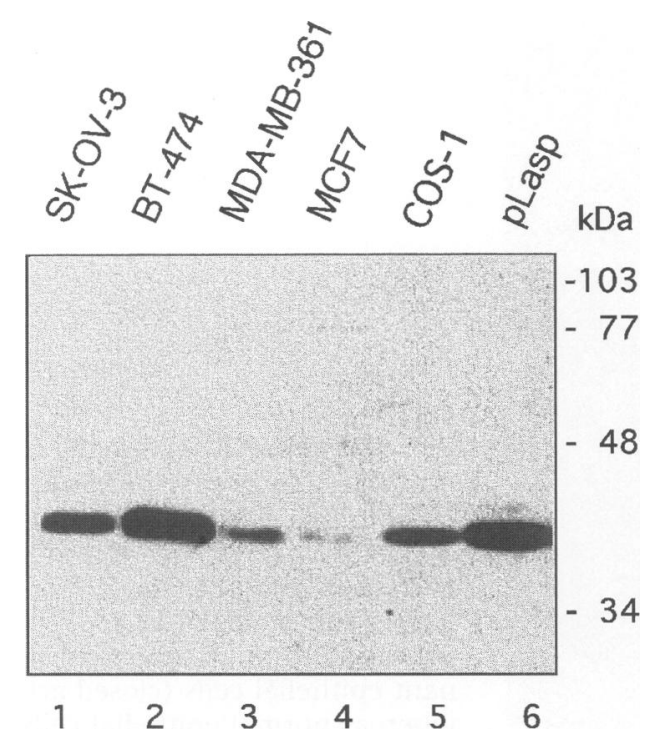

Fig. 2. Expression of Lasp-1 in cell lines. The pab805 anti-Lasp-1 antibody was used to detect Lasp-1 protein by Western blot analysis of crude cell lysates (6 $\mu \mathrm{g}$ of total protein) from SK-OV-3 ovarian cancer and BT-474, MDA-MB-361, and MCF7 breast cancer cell lines (lanes 1-4, respectively) and from COS-1 cells untransfected (lane 5) or transfected with the human Lasp-1 cDNA cloned in the pCMVneo expression vector (pLasp, lane 6).

were also reported in other nebulin-related proteins (Fig. 1C), including nebulette, a $107 \mathrm{kD}$ cardiac muscle protein (29) and N-Rap, a $185 \mathrm{kD}$ striated muscle actin-binding protein (30). The $C$. elegans protein Ylz4 also contains two such motifs (31). In addition to these actin-binding domains, $\mathrm{N}$-Rap and Ylz4 harbor an N-terminal LIM domain (Fig. 1B), whereas nebulin contains a Cterminal SH3 domain (Fig. 1D), both of which are highly homologous to the respective domains of Lasp-1.

The presence of these two actin-binding motifs suggested that Lasp-1 may associate with the cytoskeleton through interactions with actin.

\section{Lasp-1 Expression in Human Cancer Cell Lines}

In order to study the protein expression of human and mouse Lasp-1, we generated a rabbit polyclonal antibody (pab805) using a synthetic peptide strictly conserved in human and mouse Lasp-1. Using this antibody, we performed Western blot analysis on cell extracts from various human cell lines established from ovarian cancer (SK-OV-3, Fig. 2, lane 1), breast cancer (BT-474, MDA-MB-361, MCF7, Fig. 2 lanes 2-4), and from simian COS-1 cells, wild type or transiently transfected with the human Lasp-1 cDNA (Fig. 2. lanes 5, 6). In all cell lines, the pab805 antibody detected a single band of approximately $40 \mathrm{kD}$, a molecular weight that did not correspond to that of $29 \mathrm{kD}$ deduced from the Lasp-1 open reading frame. This size discrepancy could be explained either by post-translational modifications or by the high proline content of the protein $(6.9 \%)$. The human Lasp-1 transiently expressed in COS-1 cells (Fig. 2, lane 6) showed the same molecular weight as the endogenous simian protein (Fig. 2, lane 5). Consistent with our previous observations of Lasp-1 amplification and mRNA overexpression in BT-474 and SK-OV-3 cells ([4], and our unpublished results) is the finding that the highest levels of Lasp-1 protein were observed in these malignant cell lines (Fig. 2, lanes 1, 2).

\section{In Vivo Subcellular Localization of Lasp-1 in Human Breast Carcinoma}

In human invasive breast carcinomas in which Lasp-1 was amplified and overexpressed, immunohistochemical analysis on paraffin-embedded sections showed an intense cytoplasmic staining in the malignant epithelial cells (Fig. 3). In contrast, low levels of Lasp-1 were detected in normal epithelial and stromal cells. This result is consistent with the previously described ubiquitous basal expression of Lasp-l observed by Northern blot analysis in normal human and mouse tissues $(3,4)$. Thus, in human breast carcinomas, amplification of Lasp-1 gene leads to an overexpression of the protein that is restricted to malignant epithelial cells.

\section{In Vitro Subcellular Localization of Lasp-1 in Human Breast Cancer Cells}

Confocal immunofluorescence experiments using the BT-474 and SK-OV-3 cell lines, which express high levels of Lasp-1 protein (Fig. 2, lanes 2 and 1, respectively), revealed that Lasp-1 had a diffuse cytoplasmic localization (Fig. 4), as observed in vivo in breast cancer (Fig. 3). In addition, in individual cells, Lasp-1 protein accumulated in membrane extensions including membrane rufflings at the apical side of the cell, filopodia, and lamellipodia (Fig. 4A, A-D). Since actin was known to concentrate in such cell extensions and Lasp- 1 was presumed to be an actin binding protein, colocalization experiments were performed in individual BT-474 and SK-OV-3 cells using the pab805 anti-Lasp- 1 antibody and 


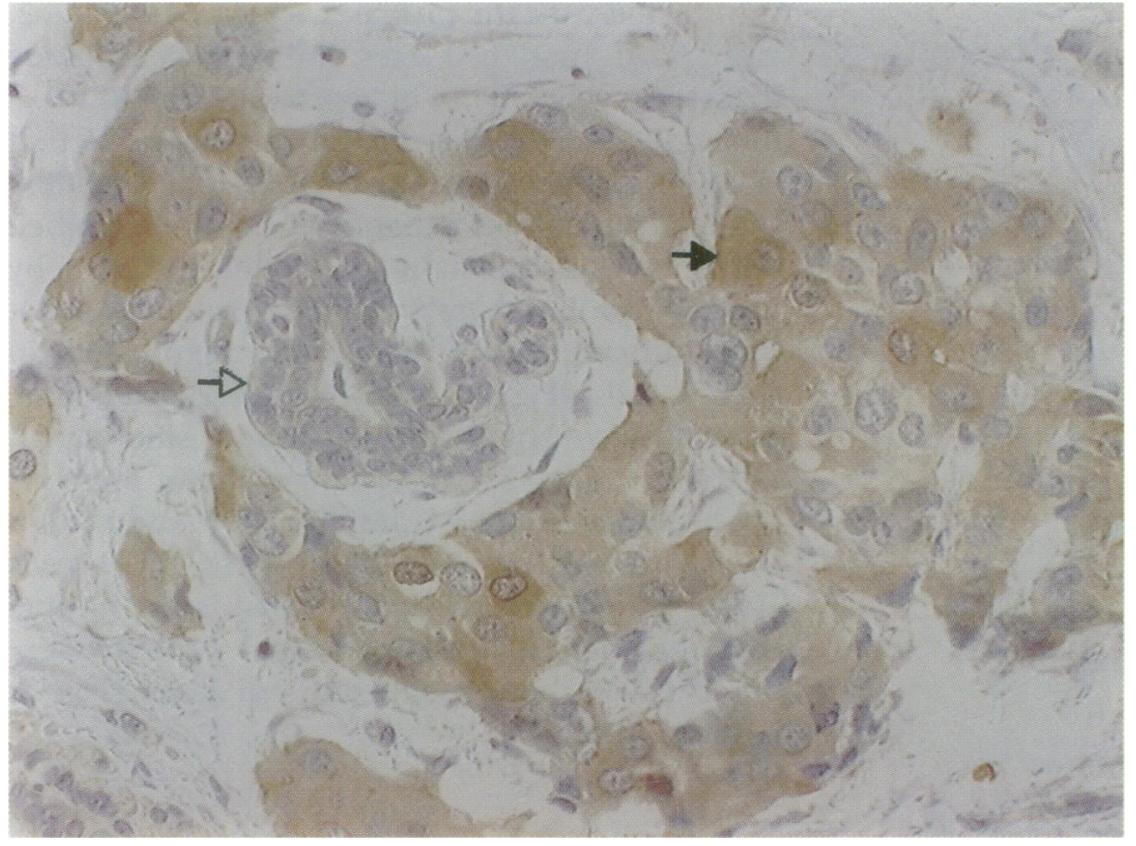

Fig. 3. Subcellular localization of Lasp-1 in breast carcinomas. Paraffin sections of human invasive breast carcinoma were immunostained using the pab805 antibody. High levels of Lasp-1 were detected in the cytoplasm of malignant epithelial cells (closed arrow) whereas normal epithelial cells showed basal levels of Lasp-1 expression (open arrow). Magnification: $\times 60$.
FITC-phalloidin to stain actin. The pattern of localization of the two proteins partially overlapped. Lasp-1 did not colocalize with the actin stress fibers (Fig. 4B and D), which consist of long bundles of actin filaments that traverse the cell and are linked to the plasma membrane at focal adhesions (32). In addition, no Lasp-1 staining was detectable at cell-cell junctions, nor at adhesion plaques which form at cell-substratum contact sites, two regions where actin was observed (data not shown). However, Lasp-1 was found to colocalize with actin in cell membrane extensions (Fig. 4B, g and 4D, m). Furthermore, treatment of BT-474 or SK-OV-3 cells with cytochalasin $\mathrm{D}$ led to a partial redistribution of Lasp- 1 in the actin aggregates that arose from the drug-induced depolymerization of actin microfilaments (Fig. 4C, j and 4E, p). These results are in favor of an interaction between Lasp-1 and the actin cytoskeleton at the site of cell membrane extensions.

\section{Lasp-1 and Actin Directly Interact}

To determine if Lasp-1 was able to bind actin, full-length (GST-Lasp), N-terminal (GST-NLasp), and C-terminal (GST-C-Lasp) versions of mouse Lasp-1 cDNA (3) were fused to GST (Fig. 5A), and the fusion proteins were expressed in COS-1 cells. AGST-pull-down assay was performed (Fig. 5B, left panel) and copurification of actin was tested by Western blot analysis using the AC-40 anti-actin antibody (Fig. 5B, right panel). In this assay, we observed that endogenous actin (Fig. 5, lane $\mathrm{l}^{\prime}$ ) copurified with GSTLasp (Fig. 5B, lane 2'), indicating that Lasp-l
Fig. 4. Lasp-1 is colocalized with actin in cell membrane extensions of human BT-474

breast and SK-OV-3 ovarian cancer cells. (A) Confocal immunofluorescent microscopy analysis of the subcellular distribution of Lasp-1 in BT-474 cells. Cells were fixed with paraformaldehyde, permeabilized, and Lasp-1 was immunostained with the pab805 polyclonal antibody and Texas Red-conjugated donkey anti-rabbit antibody. Two optical sections parallel to the cell substratum, spaced by $1 \mu \mathrm{m}$, are shown, from bottom $(a, c)$ to top $(b, d)$ of two different optical fields. The closed arrows and arrowheads show accumulation of Lasp-1 in filopodium and apical membrane extensions, respectively. Lasp- 1 is not detectable at cell-cell junctions, shown by open arrowheads. Bar, $10 \mu \mathrm{m}$. (B-E) Double labeling of Lasp-1 and actin with $(C, E)$ or without $(\mathrm{B}, \mathrm{D})$ cytochalasin $\mathrm{D}$ treatment in $\mathrm{BT}$ 474 (B, C) and SK-OV-3 (D, E) cells. Lasp-l (e, h, $\mathrm{k}, \mathrm{n}$ ) immunostaining is as in (A). Actin (f, $\mathrm{i}, \mathrm{l}, \mathrm{o}$ ) is stained with fluorescein-phalloidin. The false color imaging represents Lasp- 1 as red and actin as green and colocalization of the two proteins as yellow ( $g, j, m, p)$. cyt D, cytochalasin D. Arrows show colocalization of Lasp-1 and actin. Bar, $10 \mu \mathrm{m}$. 

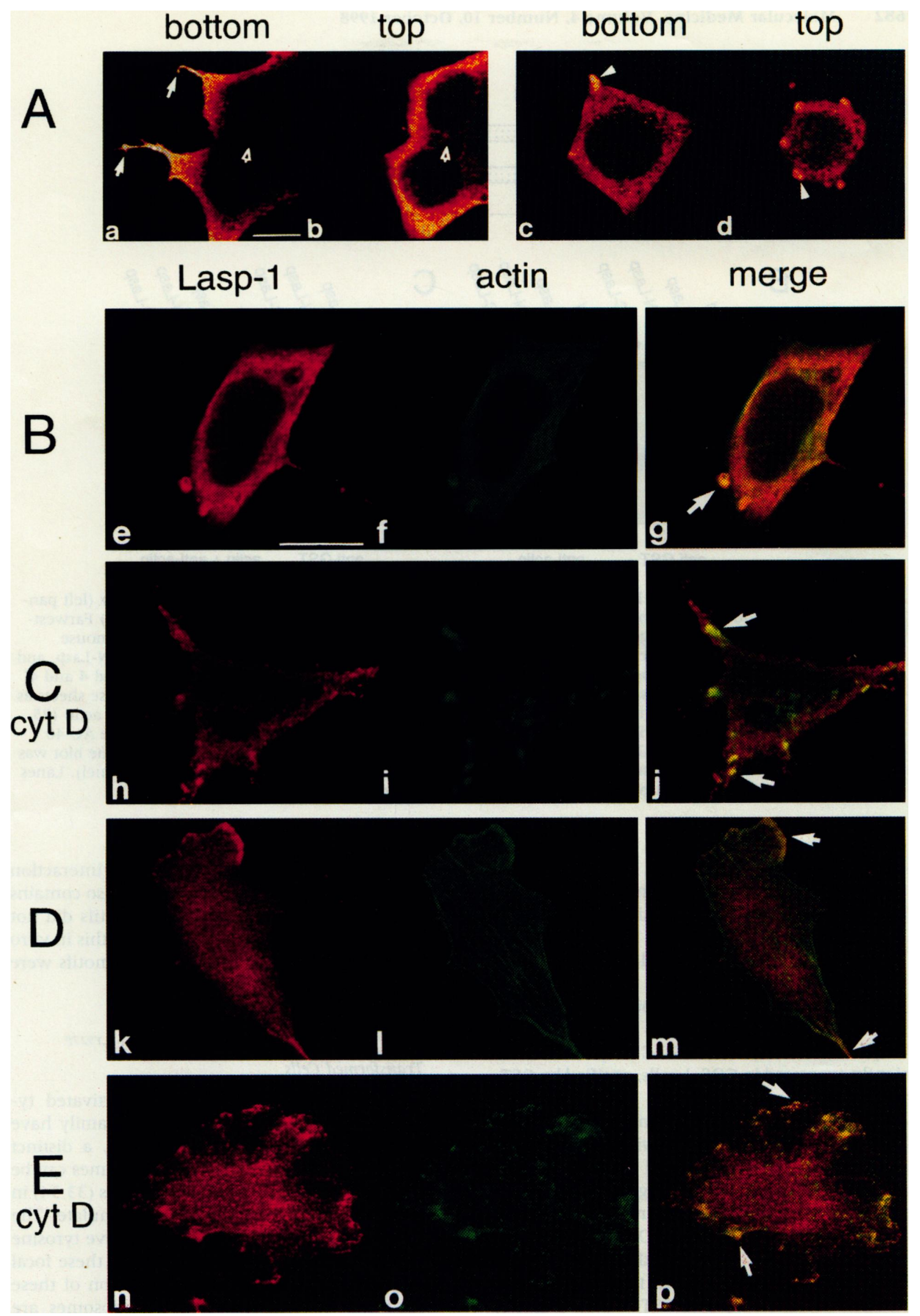

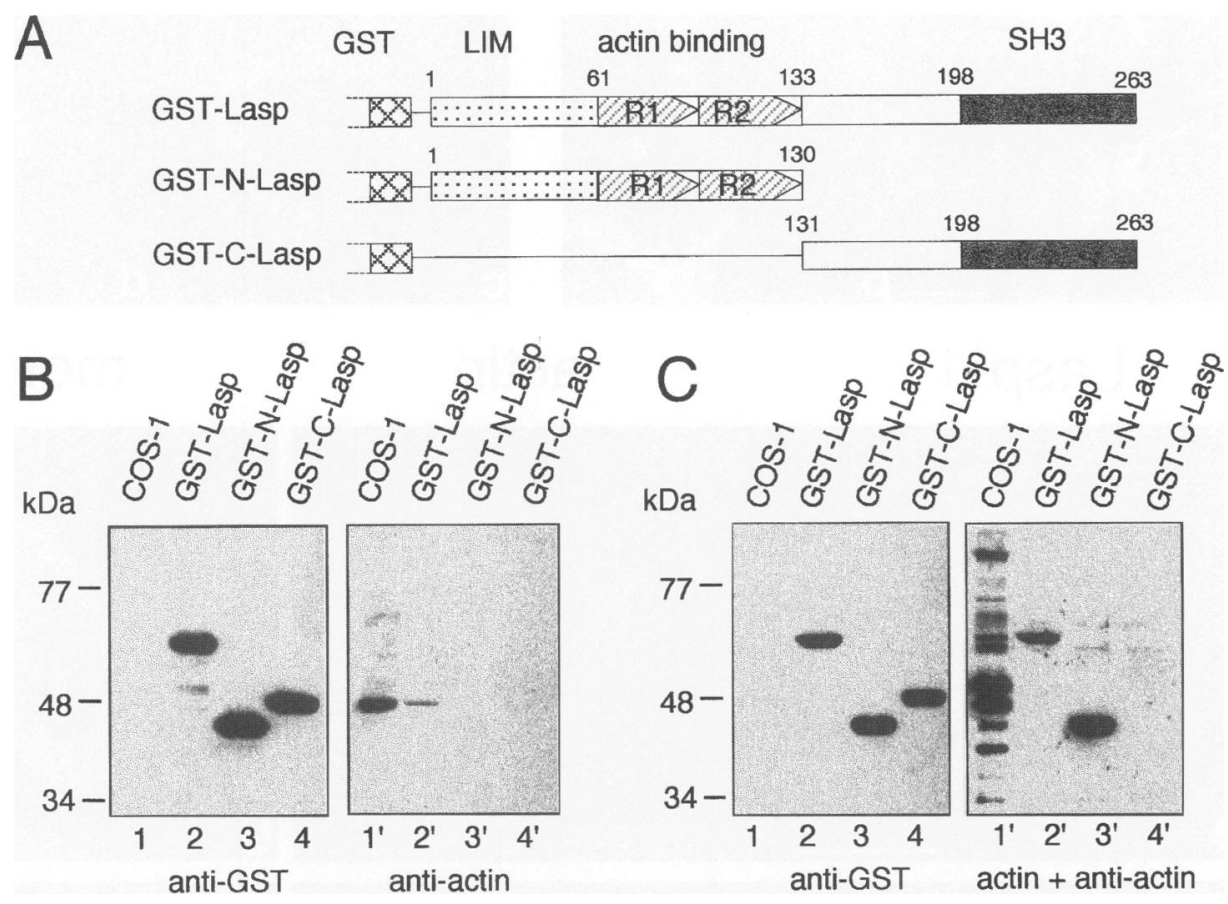

Fig. 5. Actin binding of Lasp-1. (A) Schematic representation of mouse GST-Lasp, GST-N-Lasp, and GST-C-Lasp. Symbols are as in legend of Figure $1 \mathrm{~A}$. GST is represented by a cross-hatched box. (B) Mouse Lasp-1 interacts with endogenous actin in COS-1 cells. GST-Lasp, GST-N-Lasp, and GST-C-Lasp (lanes 2 and 2', 3 and $3^{\prime}$, and 4 and $4^{\prime}$ respectively) expressed in COS-1 cells, and purified by GST-pull down were separated by SDS-PAGE and transferred to nitrocellulose. The blot was first probed with the AC-40 anti-actin antibody (right panel), stripped,

bound actin. As expected, the GST-C-Lasp construct containing the $\mathrm{SH} 3$ domain did not bind actin (Fig. 5B, lane $4^{\prime}$ ). Surprisingly, the GST-NLasp construct, harboring the R1 and R2 actin binding motifs, was also unable to trap actin in this assay (Fig. 5B, lane $3^{\prime}$ ).

To further study the actin binding capacity of Lasp-1, a gel overlay assay was carried out. GSTLasp, GST-N-Lasp, or GST-C-Lasp was transiently expressed in COS-1 cells, purified by GSTpull down assay (Fig. 5C, left panel) and analyzed by farwestern blotting (Fig. 5C, right panel). Blots were incubated with purified actin, and bound actin was revealed using the AC-40 anti-actin antibody (Fig. 5C, right panel). As expected, numerous proteins were able to interact with actin in the crude COS-1 cell extract (Fig. 5C, lane $\mathrm{l}^{\prime}$ ). Concerning the Lasp-1 recombinant proteins, the binding to actin was observed with GST-Lasp and GST-N-Lasp (Fig. 5C, lanes $2^{\prime}$ and $3^{\prime}$ ), both constructs containing the

then reprobed with an anti-GST antibody (left panel). Lanes 1 and I': COS-l cell lysate. (C) Farwestern experiment showing the binding of mouse Lasp- 1 to purified actin. GST-Lasp, GST-N-Lasp, and GST-C-Lasp (lanes 2 and 2', 3 and 3', and 4 and 4' respectively) immobilized on nitrocellulose sheets as in (B) were incubated $2 \mathrm{hr}$ with purified actin (25 $\mu \mathrm{g} / \mathrm{ml}$ ) before immunodetection with the AC-40 anti-actin antibody (right panel). The same blot was reprobed with anti-GST antibody (left panel). Lanes 1 and $1^{\prime}$ : COS-1 cell lysate.

$\mathrm{R} 1$ and $\mathrm{R} 2$ actin-binding motifs. This interaction was specific, since GST-C-Lasp that also contains GST but is devoid of R1 and R2 motifs did not bind actin (Fig. 5C, lane $4^{\prime}$ ). Thus, in this in vitro condition, R1 and R2 actin-binding motifs were functional.

\section{Lasp-1 Is Localized in Podosomes of c-Src ${ }^{Y 527 F}$ Transformed Cells}

Fibroblastic cells transformed by activated tyrosine kinase oncogenes of the Src family have been shown to develop podosomes, a distinct type of membrane extension. Podosomes can be regarded as modified adhesion plaques $(33,34)$ in which the oncogenic proteins accumulate. The c-Src ${ }^{\mathrm{Y} 27 \mathrm{~F}}$ mutant, showing constitutive tyrosine kinase activity (35), was localized to these focal adhesion sites, leading to an alteration of these particular cell structures (15). Podosomes are also known to be enriched in cytoskeletal and 

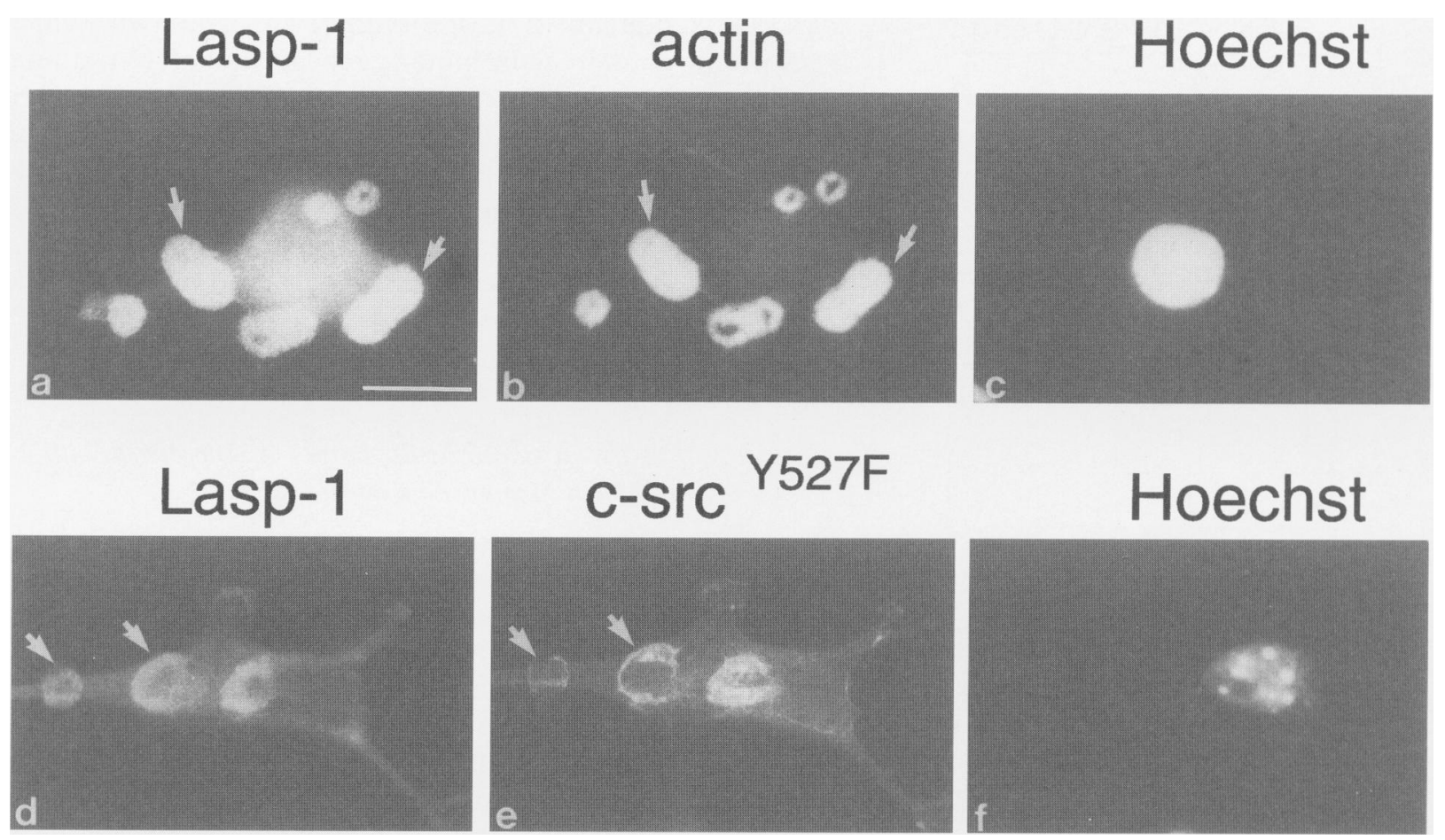

\section{Hoechst}

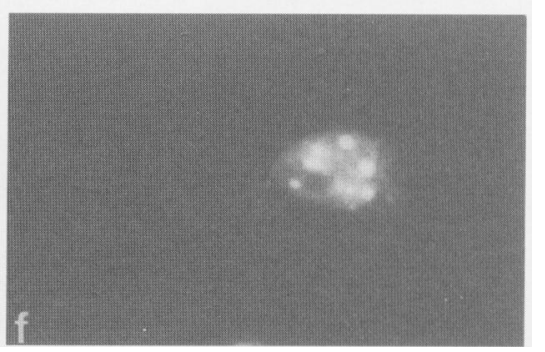

Fig. 6. Localization of Lasp-1 in transformed 3T3/A cells. 3T3/A cells, transiently overexpressing mouse Lasp-1, were fixed with paraformaldehyde, permeabilized, and immunostained with the pab805 anti-Lasp-1 polyclonal antibody ( $a$ and d), and either immunostained with the 327 monoclonal anti-src antibody (e) or labelled with fluorescein-phalloidin to stain actin (b). Nuclei were stained with Hoechst 33258 (c and f). Lasp-1 was colocalized with actin (a and b), or c-Src ${ }^{\text {Y527F }}$ (d and e) in podosomes (arrows). Bar, $10 \mu \mathrm{m}$. associated proteins (33,36). Accordingly, we observed that the 3T3/A C-Src ${ }^{\mathrm{Y} 27 \mathrm{~F}}$-transformed NIH3T3 mouse fibroblastic cell line $(19,20)$ showed high levels of actin and $\mathrm{c}-\mathrm{Src}^{\mathrm{Y} 527 \mathrm{~F}}$ in their podosomes (Fig. $6 \mathrm{~b}$ and e, respectively). These cells were transiently transfected with the pAT4Lasp vector in order to overproduce mouse Lasp-1. As expected, Lasp-1 protein was preferentially localized to 3T3/A podosomes (Fig. 6a and d). Thus, as observed for overexpressed endogenous Lasp- 1 in BT-474 epithelial breast cancer cells, in $3 \mathrm{~T} 3 / \mathrm{A} \mathrm{c}^{\mathrm{c}-\mathrm{Src}}{ }^{\mathrm{Y} 27 \mathrm{~F}}$ transformed fibroblasts, overexpressed Lasp-1 colocalized with actin in membrane extensions.

Lasp-I Is Tyrosine Phosphorylated in c-Src $^{\text {Y527F }}$ Transformed Cells

Podosomes were reported to be enriched in phosphotyrosine-containing proteins $(33,36)$. Since Lasp-1 colocalized with $\mathrm{c}-\mathrm{Src}^{\mathrm{Y} 527 \mathrm{~F}}$ in podosomes of 3T3/A cells, we investigated the tyrosine phosphorylation status of Lasp-1 in these transformed cells. Lasp-1 contains 16 tyrosines, some of which are in the context of potential tyrosine phosphorylation sites (37), suggesting that the protein could be phosphorylated on these residues (4). This hypothesis was tested by Western blot analysis using the $4 \mathrm{Gl} 0$ monoclonal antiphosphotyrosine antibody. Cell extracts were prepared from 3T3, 3T3/N, and 3T3/A cell lines (Fig. 7), which are immortalized, immortalized and expressing c-Src protooncogene, and c-Src ${ }^{\mathrm{Y} 527 \mathrm{~F}}$-transformed mouse fibroblastic cell lines, respectively. As previously reported (38), the transformation of fibroblastic cells by $\mathrm{c}-S r c^{\mathrm{Y} 527 \mathrm{~F}}$ mutant leads to a dramatic increase in the phosphorylation of numerous proteins (Fig. 7, lane 2). Lasp-1 tyrosine phosphorylation was not detectable in $3 \mathrm{~T} 3 / \mathrm{N}$ and $3 \mathrm{~T} 3 / \mathrm{A}$ crude extracts (Fig. 7, lanes 1 and 2). However, after Lasp-1 immunopurification with the pab805 antibody, we observed the presence of a doublet showing tyrosine phosphorylation of Lasp-1 in 3T3/A cells (Fig. 7, lane 5), but not in 3T3 and 3T3/N cells (Fig. 7, lanes 3 and 4). Lasp-1 staining of the same blot using pab805 antibody showed that similar amounts of Lasp-1 protein 


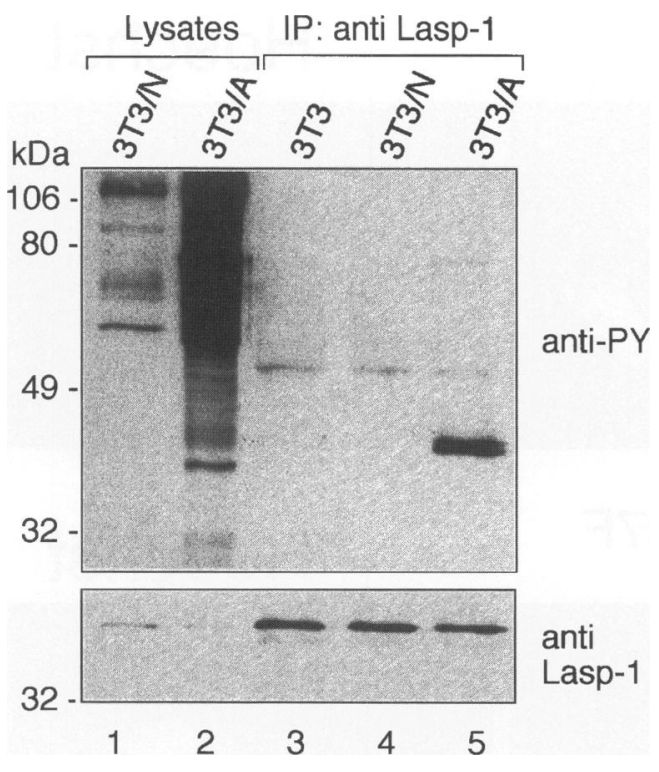

Fig. 7. Tyrosine phosphorylation of Lasp-1 in 3T3/A cells transformed with the c-SrcY527F variant. Crude extracts from $3 \mathrm{~T} 3 / \mathrm{N}$ (lane 1 ) and 3T3/A (lane 2), and Lasp-1 immunopurified with the pab805 antibody from 3T3 (lane 3), 3T3/N (lane 4 ), and 3T3/A (lane 5) were analyzed using the 4G10 antiphosphotyrosine (anti PY) antibody (upper panel). The same blot was stripped and probed with the pab805 antibody (lower panel).

were present in each lysate (Fig. 7, lower panel). The doublet could reflect the presence of several tyrosine phosphorylation sites on Lasp-1 and/or a concomitant phosphorylation of serine/threonine residues. Alternatively, a new tyrosinephosphorylated protein could have copurified with Lasp-1. These experiments demonstrate that Lasp-1 is tyrosine phosphorylated in c-Src ${ }^{\mathrm{Y} 527 \mathrm{~F}}$-transformed cells.

\section{Discussion}

Lasp-1: A Novel Type of Protein Containing LIM, SH3, and Actin-Binding Domains

LIM and SH3 domains were previously identified in the sequence of Lasp- $\mathrm{I}$ in the $\mathrm{N}$-terminal and $\mathrm{C}$-terminal regions of the protein, respectively (4). In the present study, we observed that, in addition, Lasp-l contains two actin-binding motifs. These actin-binding sites are highly homologous to those found in nebulin, the main composition of which is 185 repeats of such a motif (26-28). The structural organization of Lasp-1 presents homologies with nebulin, which contains actin-binding repeats and a $\mathrm{C}$-terminal $\mathrm{SH}_{3}$ domain (27), and with N-Rap and Ylz4, which contain actin-binding repeats and an $\mathrm{N}$-terminal LIM domain $(30,31)$. Lasp- 1 is the first described protein containing LIM, SH3, and actin-binding domains, thus constituting a novel type of protein. From its particular structure, we hypothesized that Lasp-1 is a modular protein involved in protein-protein interactions, and most probably interacting with actin.

\section{In Breast Cancer Cells, Lasp-1 Is Colocalized with Actin in Membrane Extensions}

The Lasp-1 gene was reported to be amplified and its mRNA overexpressed in $12 \%$ of human breast cancers (2). Consistant with this, in a human breast carcinoma overexpressing the Lasp-1 gene, we observed high levels of Lasp-1 protein. Moreover, overexpressed Lasp-1 protein was localized in the cytoplasm of malignant epithelial cells, whereas normal epithelial and stromal cells exhibited a basal level of Lasp-1 expression, as would be expected from its ubiquitous pattern of mRNA expression observed in normal tissues $(3,4)$. In vitro, confocal analyses revealed that, in addition to the homogeneous cytoplasmic distribution of Lasp-1, the protein accumulated at higher levels in the cell membrane extensions.

Malignant cells are known to undergo dramatic cytoskeletal modifications, notably in order to acquire motility properties (39). Migrating cells exhibit a polarized morphology, including membrane ruffling and lamellipodia at the leading edge of the cell, and filopodia, consisting of short protruding bundles of actin filaments (40). Membrane extensions develop following the local polymerization of actin, leading to a compact meshwork of actin filaments and an increased concentration of components associated with the cytoskeleton (40). Colocalization experiments performed in BT-474 and SK-OV-3 cells showed that Lasp-1 and actin were colocalized at cell membrane extensions and were still colocalized in aggregates following actin depolymerization by cytochalasin $\mathrm{D}$. According to the widespread distribution of actin filaments in cells, Lasp-1 was not always colocalized with actin. Lasp- 1 was not observed along stress fibers nor at cell-substratum contact sites. Thus, the colocalization of Lasp- 1 and actin in membrane extensions is compatible with a possible interaction of the two proteins. In order to test this hypothesis, further in vivo and in vitro experiments were performed. 


\section{Lasp-1 Is an Actin-Binding Protein}

Copurification experiments indicated that actin was associated with Lasp-1 in vivo. In addition, this association was shown to be direct in vitro using a gel overlay assay. Finally, R1 and R2 actin-binding motifs were likely to be responsible for this interaction as the truncated form of Lasp-1, harboring these motifs (GST-N-Lasp), was able to bind actin in vitro, whereas GST-CLasp, lacking these motifs, was nonfunctional in this assay.

However, an in vivo actin-binding assay showed that, although containing the R1 and R2 sites, the GST-N-Lasp recombinant protein was unable to bind endogenous actin. As shown before, Lasp-1 is colocalized with actin in membrane extensions. In addition, $\mathrm{SH} 3$ domains have been shown to be involved in targeting processes of proteins to specific subcellular sites, e.g., Grb2 to membrane ruffling (18), and c-Src ${ }^{\text {Y527F }}$, paxillin, and Cas to focal adhesion (15-17). Moreover, the $\mathrm{SH} 3$ domain of nebulin is thought to be the first point of attachment of the protein to microfilaments in vertebrate muscle, preceding the formation of contacts made through actinbinding sites (41). In a similar manner, the SH3 domain of Lasp-1, which is deleted in GST-NLasp, could help in the localization of Lasp-1 to specific sites of the cytoskeleton, such as membrane extensions, where it could interact with actin. This hypothesis is consistent with the in vitro experiments where GST-N-Lasp was able to bind actin. Altogether, these results indicated that Lasp- 1 is a novel actin-binding protein, and its actin-binding sites are functional.

\section{Lasp-1 Is Colocalized with Activated c-Src in 3T3/A Transformed Cells}

Podosomes, another type of membrane extension, are structures considered to be modified adhesion plaques $(33,34)$. They are characterized by decreased cell adhesiveness and are found in cells that tend to be motile, such as monocytes, osteoclasts, and many transformed cells, and most notably in cells transformed by viruses carrying oncogenes encoding tyrosine kinases such as $\operatorname{src}(33,34,36)$. It has been shown that actin and $\mathrm{C}-\mathrm{Src}^{\mathrm{Y} 527 \mathrm{~F}}$ both accumulate in podosomes $(15,33)$. Since the 3T3/A-transformed cell line that constitutively expressed the activated mutant $\mathrm{c}-\mathrm{Src}^{\mathrm{Y} 527 \mathrm{~F}}$ develops these particular membrane extensions, the Lasp-1 protein was transiently overexpressed in this cell line. Lasp-1 colocalized with both actin and c-Src ${ }^{\mathrm{Y} 527 \mathrm{~F}}$ in po- dosomes. The recruitment of Lasp-1 in these modified adhesion plaques where mobile cells adhere transiently to the extracellular matrix suggests that Lasp-1 may participate in regulating the migration processes of such transformed cells.

Lasp-1 Is Phosphorylated on Tyrosine Residues in c-Src ${ }^{Y 527 F}$ Transformed Cells

Numerous cytoskeleton-associated proteins, including FAK, paxillin, and cortactin, have been reported to be phosphorylated directly or indirectly by c-Src, or hyperphosphorylated upon cell transformation by active c-Src mutants $(32,42)$. Similarly, hyperphosphorylation of Lasp- 1 was observed in the 3T3/A cell line transformed by $\mathrm{c}-\mathrm{Src}^{\mathrm{Y} 527 \mathrm{~F}}$. However, phosphorylation of Lasp-1 upon C-Src ${ }^{\text {Y527F }}$ transformation is not a direct event, since using in vitro assays, we were unable to demonstrate neither interaction between Lasp-1 and c-Src ${ }^{\text {Y527F }}$ nor direct phosphorylation of Lasp-1 by this tyrosine kinase (our unpublished results). Thus, an unidentified protein tyrosine kinase activated in $\mathrm{C}-\mathrm{Src}^{\mathrm{Y} 527 \mathrm{~F}}$ transformed cells must be responsible for Lasp-1 phosphorylation.

Altogether, our results show that Lasp-1, which contains $\mathrm{R} 1$ and $\mathrm{R} 2$ actin-binding sites in addition to LIM and SH3 domains, is a new type of actin-binding protein. It is now becoming clear that the cytoskeleton not only affects the shape and motility of cells but is also intimately involved in the transduction of extracellular signals through the recruitment of components of signal transduction cascades (43). It is tempting to speculate that Lasp-1 might be an adaptor protein involved in such processes.

\section{Acknowledgments}

We thank C. Fode for critical reading of the manuscript. We are very grateful to G. Duval for the generation of the pab805 anti-Lasp-1 antibody. We thank B. Chatton and M. Vigneron for the gift of the $\mathrm{pBC}$ and pAT4 vectors, respectively, and D. Morrison, J. Brugge, and Y. Lutz for the gift of the $4 \mathrm{G} 10$ monoclonal anti-phosphotyrosine, 327 anti-src, and anti-GST antibodies, respectively. This work was supported by funds from the Institut National de la Santé et de la Recherche Médicale, the Centre National de la Recherche Scientifique, the Centre Hospitalier Universitaire Régional, the Bristol-Myers Squibb 
Pharmaceutical Research Institute, the Association pour la Recherche sur le Cancer, the Ligue Nationale Française contre le Cancer and the Comité du Haut-Rhin, the Fondation de France, the Programme Hospitalier de Recherche Clinique 1995, the Biomed 2 (contract no. BMH4CT96-0017) and BIOTECH 2 (contract no. ERBBIO4CT96-0464), and by a grant to $P$. Chambon from the Fondation Jeantet. V.S. was a recipient of a postdoctoral fellowship from the Ligue Nationale Française contre le Cancer (Comité du Haut-Rhin).

\section{References}

1. Tomasetto C, Régnier C, Moog-Lutz C, et al. (1995) Identification of four novel human genes amplified and overexpressed in breast carcinoma and localized to the q11-q21.3 region of chromosome 17. Genomics 28: 367-376.

2. Bièche I, Tomasetto C, Régnier $\mathrm{CH}$, Moog-Lutz C, Rio MC, Lidereau R. (1996) Two distinct amplified regions at $17 q 11-q 21$ involved in human primary breast cancer. Cancer Res. 56: 3886-3890.

3. Schreiber V, Masson R, Linares JL, Mattei MG, Tomasetto C, Rio MC. (1998) Chromosomal assignment and expression pattern of the murine Lasp-1 gene. Gene 207: 171-175.

4. Tomasetto C, Moog-Lutz C, Régnier $\mathrm{CH}$, Schreiber V, Basset P, Rio MC. (1995) Lasp-1 (MLN 50) defines a new LIM protein subfamily characterized by the association of LIM and SH3 domains. FEBS Lett. 373: 245-249.

5. Sanchez-Garcia I, Rabbitts TH. (1994) The LIM domain: a new structural motif found in zincfinger-like proteins. Trends Genet 10: 315-320.

6. Gill GN. (1995) The enigma of LIM domains. Structure 3: 1285-1289.

7. Feuerstein R, Wang X, Song D, Cooke NE, Liebhaber SA. (1994) The LIM/double zinc-finger motif functions as a protein dimerization domain. Proc. Natl. Acad. Sci. U.S.A. 91: 10655-10659.

8. Schmeichel KL, Beckerle MC. (1994) The LIM domain is a modular protein-binding interface. Cell 79: $211-219$.

9. Wadman I, Li J, Bash RO, Forster A, Osada H, Rabbitts TH, Baer R. (1994) Specific in vivo association between the bHLH and LIM proteins implicated in human $\mathrm{T}$ cell leukemia. $E M B O \mathrm{~J}$ 13: 4831-4839.

10. Wu RY, Gill GN. (1994) LIM domain recognition of a tyrosine-containing tight turn. J. Biol. Chem. 269: 25085-25090.

11. Cohen GB, Ren R, Baltimore D. (1995) Modular binding domains in signal transduction proteins. Cell 80: 237-248.

12. Arber S, Halder G, Caroni P. (1994) Muscle LIM protein, a novel essential regulator of myogenesis, promotes myogenic differentiation. Cell 79: 221231.

13. Seidel-Dugan C, Meyer BE, Thomas SM, Brugge JS. (1992) Effects of SH2 and SH3 deletions on the functional activities of wild-type and transforming variants of c-Src. Mol. Cell Biol. 12: 1835-1845.

14. Mayer BJ, Baltimore D. (1994) Mutagenic analysis of the roles of $\mathrm{SH} 2$ and $\mathrm{SH} 3$ domains in regulation of the Abl tyrosine kinase. Mol. Cell Biol. 14: 2883-2894.

15. Kaplan KB, Bibbins KB, Swedlow JR, Arnaud M, Morgan DO, Varmus HE. (1994) Association of the amino-terminal half of c-Src with focal adhesions alters their properties and is regulated by phosphorylation of tyrosine 527. EMBO J. 13: 4745-4756.

16. Brown MC, Perrotta JA, Turner CE. (1996) Identification of LIM3 as the principal determinant of paxillin focal adhesion localization and characterization of a novel motif on paxillin directing vinculin and focal adhesion kinase binding. J. Cell Biol. 135: 1109-1123.

17. Nakamoto T, Sakai R, Honda H, et al. (1997) Requirements for localization of pl30cas to focal adhesions. Mol. Cell Biol. 17: 3884-3897.

18. Bar-Sagi D, Rotin D, Batzer A, Mandiyan V, Schlessinger J. (1993) SH3 domains direct cellular localization of signaling molecules. Cell 74: 83-91.

19. Kmiecik TE, Shalloway D. (1987) Activation and suppression of pp60c-src transforming ability by mutation of its primary sites of tyrosine phosphorylation. Cell 49: 65-73.

20. Boeuf H, Murphy J, Bibbins KB, Varmus HE. (1995) Binding in vitro of phosphotyrosine-containing proteins to pp60c-src SH2 domain does not correlate with CEF transformation. Oncogene 10: 433-438.

21. Baker SJ, Markowitz S, Fearon ER, Willson JK, Vogelstein B. (1990) Suppression of human colorectal carcinoma cell growth by wild-type p53. Science 249: 912-915.

22. Chatton B, Bahr A, Acker J, Kedinger C. (1995) Eukaryotic GST fusion vector for the study of protein-protein associations in vivo: application to interaction of ATFa with Jun and Fos. Biotechniques 18: 142-145.

23. Tribouley C, Lutz P, Staub A, Kedinger C. (1994) The product of the adenovirus intermediate gene IVa2 is a transcriptional activator of the major late promoter. J. Virol. 68: 4450-4457.

24. Chen C, Okayama H. (1987) High-efficiency transformation of mammalian cells by plasmid DNA. Mol. Cell Biol. 7: 2745-2752.

25. Rio MC, Bellocq JP, Gairard B, et al. (1987) Specific expression of the pS2 gene in subclasses of breast cancers in comparison with expression of the estrogen and progesterone receptors and the oncogene ERBB2. Proc. Natl. Acad. Sci. U.S.A. 84: 9243-9247.

26. Pfuhl M, Winder SJ, Pastore A. (1994) Nebulin, a 
helical actin binding protein. EMBO J. 13: 17821789.

27. Labeit S, Kolmerer B. (1995) The complete primary structure of human nebulin and its correlation to muscle structure. J. Mol. Biol. 248: 308315.

28. Wang K, Knipfer M, Huang QQ, et al. (1996) Human skeletal muscle nebulin sequence encodes a blueprint for thin filament architecture. Sequence motifs and affinity profiles of tandem repeats and terminal SH3. J. Biol. Chem. 271: 40344314.

29. Moncman CL, Wang K. (1996) Nebulette: a 107 $\mathrm{kDa}$ nebulin-like protein in cardiac muscle. Cell Motil. Cytoskeleton 32: 205-225.

30. Luo G, Zhang JQ, Nguyen TP, Herrera AH, Paterson B, Horowits R. (1997) Complete cDNA sequence and tissue localization of N-RAP, a novel nebulin-related protein of striated muscle. Cell. Motil. Cytoskeleton 38: 75-90.

31. Wilson R, Ainscough R, Anderson K, et al. (1994) $2.2 \mathrm{Mb}$ of contiguous nucleotide sequence from chromosome III of $\mathrm{C}$. elegans [see comments]. $\mathrm{Na}$ ture 368: 32-38.

32. Burridge K, Chrzanowska-Wodnicka M. (1996) Focal adhesions, contractility, and signaling. Annu. Rev. Cell Dev. Biol. 12: 463-518.

33. Tarone G, Cirillo D, Giancotti FG, Comoglio PM, Marchisio PC. (1985) Rous sarcoma virus-transformed fibroblasts adhere primarily at discrete protrusions of the ventral membrane called podosomes. Exp. Cell Res. 159: 141-157.

34. Marchisio PC, Cirillo D, Teti A, Zambonin-Zallone A, Tarone G. (1987) Rous sarcoma virus-transformed fibroblasts and cells of monocytic origin display a peculiar dot-like organization of cytoskeletal proteins involved in microfilament- membrane interactions. Exp. Cell Res. 169: 202214.

35. Cartwright CA, Eckhart W, Simon S, Kaplan PL. (1987) Cell transformation by pp60c-src mutated in the carboxy-terminal regulatory domain. Cell 49: 83-91.

36. Burridge K. (1986) Substrate adhesions in normal and transformed fibroblasts: organization and regulation of cytoskeletal,membrane and extracellular matrix components at focal contacts. Cancer Rev. 4: 18-78.

37. Songyang Z, Shoelson SE, Chaudhuri $M$, et al. (1993) SH2 domains recognize specific phosphopeptide sequences. Cell 72: 767-778.

38. Reynolds AB, Kanner SB, Wang HC, Parsons JT. (1989) Stable association of activated pp60src with two tyrosine-phosphorylated cellular proteins. Mol. Cell Biol. 9: 3951-3958.

39. Lester BR, McCarthy JB. (1992) Tumor cell adhesion to the extracellular matrix and signal transduction mechanisms implicated in tumor cell motility, invasion and metastasis. Cancer Metastasis Rev. 11: 31-44.

40. Lauffenburger DA, Horwitz AF. (1996) Cell migration: a physically integrated molecular process. Cell 84: 359-369.

41. Pfuhl M, Winder SJ, Castiglione-Morelli MA, Labeit S, Pastore A. (1996) Correlation between conformational and binding properties of nebulin repeats. J. Mol. Biol. 257: 367-384.

42. Wu H, Reynolds AB, Kanner SB, Vines RR, Parsons JT. (1991) Identification and characterization of a novel cytoskeleton-associated pp60src substrate. Mol. Cell Biol. 11: 5113-5124.

43. Geiger B, Karsenti E. (1997) Cytoskeleton. Curr. Opin. Cell Biol. 9: 1-3. 